\title{
THE AUTHORS REPLY:
}

Re: "Constitutive melanin in cell wall of etilogic agent of Lobo's disease"

Bauru, july 8, 1999

Dear Sir,

We appreciate the letter from Dr. Franco, regarding our paper describing the presence of melanin in the cell walls of Lacazia loboi ${ }^{1}$, the new name for the etiologic agent of Logo's disese ${ }^{3}$.

Masson adapted Fontana's method to stain melanin and other silver-reducing granules such as those in argentaffin cells ${ }^{1}$. Melanin and polyphenolic compounds are known to combine with silver salts, reducing them to a black metalic state. The duration of the immersion in a silver bath is critical for detecting melanin. Masson recommended $8 \mathrm{~h}$ as the maximum time. When the immersion is prolonged beyond $8 \mathrm{~h}$, the reaction loses its specificity for melanin, and other silver-reducing components can be stained black. KWON-CHUNG et al. ${ }^{1}$ showed that the cells of Cryptococcus neoformans and $C$. bacillisporus in tissue or from cultures grown on malt extract agar stained dark brown when they were preferred by these authors for differentiating C. neoformans and C. bacillisporus from other fungi. As mentioned in page 9 of our paper, according to WARKET et al. ${ }^{5}$, various substances such as formalin, iron, and lipofuscin also reduce silver by the Masson-Fontana procedure. It is important to note that basidiomycetes such as $C$. neoformans have different precursors for their melanin biosynthetic pathway than ascomycetous fungi ${ }^{2}$.

We performed the Fontana-Masson technique in two different manners: incubation for $18 \mathrm{~h}$ and by microwave with no detectable difference in staining. These two methods were done to L. loboi and P. brasiliensis in tissue sections. The organisms showed different results as described in our paper, i.e., abscence of staining in P. brasiliensis in constrast to the positive staining in I. loboi. The validity of the use of this stain for staining these two ascomycetous fungi is apparent.

\section{REFERENCES}

1. KWON-CHUNG, K.J.; HILL, W.B. \& TINNEL, S.B. - Antioxidant funtion of fungal melanin. J. Bact., 175: 7102-7104, 1981.

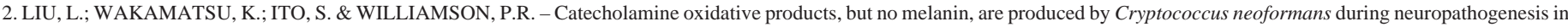
mice. Infect. Immun., 75: 108-112, 1999.

3. TABORDA, P.R.O.; TABORDA, V.B.A. \& McGINNIS, M.R. - Lacazia loboi gen. nov., comb. nov., the etiologic agent of lobomycosis. J. clin. Microbiol., 37: 2031-2033, 1999.

4. TABORDA, V.B.A.; TABORDA, P.R.O. \& McGINNIS, M.R. -Constitutive melanin in the cell wall of the etiologic agent of Lobos disease. Rev. Inst. Med. trop. S. Paulo, 41: 9-12, 1999.

5. WARKEL, R.I.; LUNA, L.G. \& HELWIG, E.B. - A modified Warthin-Starry procedure at low pH for melanin. Amer. J. clin. Path., 73: 812-815, 1980.

Dra. Valeria A. Taborda

R. Azarias Leite 10-38 apto. 82

17015'210 Bauru/SP

E-mail: fungi@blv.com.br 